\title{
Immunological response to a Staphylococcus aureus fibronectin-binding protein
}

\author{
P. CIBOROWSKI†, J.-I. FLOCK* and T. WADSTRÖM
}

Department of Medical Microbiology, University of Lund, Sölvegatan 23, S-223 62 Lund and *Center for Biotechnology, Karolinska Institute, Novum, S-141 52 Huddinge, Sweden

\begin{abstract}
Summary. A protein (gal-FnBP), constructed by fusion of the genes encoding $\beta$-galactosidase of Escherichia coli and the binding domains of fibronectin-binding protein (FnBP) of Staphylococcus aureus was used. FnBP is a surface protein responsible for attachment of bacteria to extracellular matrix of various host tissues. Gal-FnBP is more stable and can be produced in larger quantities than native FnBP. The binding specificity of this fusion protein was established in a Western blot analysis. Treatment of gal-FnBP with formalin inactivated the binding capacity of the protein but immunogenicity was retained. Immunisation of mice with formalin-treated gal-FnBP resulted in high antibody titres against the fibronectinbinding part of this fusion protein. These antibodies were measured by their ability to block the specific binding of fibronectin to gal-FnBP in a blocking assay. Sera raised against formalin-treated gal-FnBP and non-treated gal-FnBP blocked this binding to 40 and $25 \%$ respectively, thereby indicating the usefulness of gal-FnBP as a vaccine component.
\end{abstract}

\section{Introduction}

Attachment of bacterial pathogens to host tissues is an initial step in colonisation and the development of many infections. ${ }^{1}$ The ability of bacteria to bind to fibronectin, different types of collagen, laminin and vitronectin is believed to represent specific recognition of extracellular host tissue components. ${ }^{2-6}$ Fibronectin was the first host protein postulated to mediate bacterial attachment and is recognised by several species including staphylococci, streptococci, mycobacteria and Treponema pallidum. ${ }^{7}$ It has an $\mathrm{M}_{\mathrm{r}}$ of $440 \mathrm{kDa}$, and is present in soluble form in plasma, body secretions and cerebrospinal fluid as well as in an insoluble form in extracellular matrices. ${ }^{8}$ Different domains of the fibronectin molecule bind to eukaryotic and bacterial cells. ${ }^{1}$

Adhesion of staphylococci to various tissues involves non-specific, hydrophobic interactions, as well as biospecific interactions, via binding proteins. ${ }^{9}$ Staphylococci and streptococci interact with two domains on the fibronectin molecule, one site located in the amino-terminal and another in the carboxyterminal part of fibronectin. ${ }^{10}$

One fibronectin-binding protein (FnBP) from Staphylococcus aureus $(210 \mathrm{kDa})$ has been purified from strain Newman. ${ }^{11}$ The gene encoding this FnBP has been cloned $^{12}$ and the nucleotide sequence de-

Received 2 Jan. 1992; revised version accepted 2 March 1992. $\dagger$ Permanent address: National Institute of Hygiene, Department of Bacteriology, Chocimska 24, 00-791 Warsaw, Poland. termined. Four binding domains next to each other in the protein were then identified.$^{13}$ FnBP from $S$. aureus was difficult to purify and was unstable ${ }^{11}$ (G. Fröman, personal communication). To enable further studies of FnBP, a gene fusion was made such that the fibronectin binding domain of FnBP was fused with $\beta$ galactosidase from Escherichia coli.

Because $S$. aureus FnBP seems to play a crucial role in tissue colonisation, this study set out to explore the possibility of blocking this attachment with antibodies directed against FnBP.

\section{Materials and methods}

\section{Chemicals}

Fibronectin (Fn) from bovine plasma was kindly provided by Medicarb, Stockholm, Sweden. Highly purified Fn from human plasma ${ }^{14}$ was kindly provided by Janos Erdei (Lund, Sweden). ${ }^{125}$ I was purchased from Amersham Sweden AB; Iodobeads were obtained from Pierce (Rockford, IL, USA), bovine serum albumin fraction $\mathrm{V}$ and $\beta$-galactosidase from $E$. coli (E.C. 3.2.1.23) were from Sigma; $\mathrm{Al}(\mathrm{OH})_{3}$ and saponin (Quil A) were from Superfos A/S, Denmark; horseradish peroxidase-conjugated antibodies and 1,2 phenylenediamine dihydrochloride (OPD) were obtained from Dakopatts AB, Stockholm, Sweden; teichoic acid was obtained from the National Bacteriological Laboratory, Stockholm, Sweden and Protein A-Sepharose from Pharmacia AB (Uppsala, Sweden). 


\section{Bacterial strains}

Live, heat-killed $\left(80^{\circ} \mathrm{C}\right.$ for $\left.30 \mathrm{~min}\right)$ and formalinkilled $\left(5 \%\right.$ solution for $48 \mathrm{~h}$ at $\left.4^{\circ} \mathrm{C}\right)$ cells of $S$. aureus strains Newman, Cowan-I, SA 113 (83A) and SA $\mathrm{U} 305$ (a strain low in protein $\mathrm{A}$ ) were used for binding experiments in this study. Bacteria were grown in tryptic soy broth at $37^{\circ} \mathrm{C}$ for $18-24 \mathrm{~h}$ with gentle shaking. Cells in the stationary growth phase were harvested and washed three times with PBS, and resuspended in PBS to a density of $10^{9}$ cells $/ \mathrm{ml}$.

\section{Preparation of $\beta$-galactosidase-FnBP fusion protein}

The gene sequence encoding the three 38 amino-acid repeats constituting the binding portion of the FnBP ${ }^{12,13}$ was subcloned in the $\beta$-galactosidase fusion vector $\mathrm{pEX} 2 .{ }^{15}$ The resulting fusion protein contains about $12 \mathrm{kDa}$ from FnBP as a C-terminal extension of $\beta$-galactosidase that is $120 \mathrm{kDa}$. After temperature induction of the gene fusion, insoluble inclusion bodies of gal-FnBP were isolated as described previously, ${ }^{15}$ and dissolved in $8 \mathrm{M}$ urea in PBS at room temperature. The protein was then dialysed against PBS at room temperature overnight. A precipitate was formed but the major part of gal-FnBP remained soluble. This material was used in the chemical modification, immunisation, ELISA and inhibition tests.

\section{Immunisation of mice}

Inbred female BALB/c mice ( $20 \mathrm{~g}$ weight) were used. The antigen was diluted in a minimal volume of PBS and mixed with $100 \mu \mathrm{l}$ of $\mathrm{Al}(\mathrm{OH})_{3}$ suspension, incubated at $4^{\circ} \mathrm{C}$ for $24 \mathrm{~h}$, then saponin $2 \%, 25 \mu \mathrm{l}$ injection was added. Mice were randomised in groups and immunised with $0.2 \mathrm{ml} / \mathrm{mouse}$ subcutaneously. Mice were bled from the eye vein. Blood samples were left to clot at $37^{\circ} \mathrm{C}$ and sera were collected after centrifugation $(1000 \mathrm{~g}$ for $15 \mathrm{~min})$. Eight groups of mice (10 mice in each group) were immunised intravenously with four consecutive doses at 1 -week intervals. Heat- and formalin-killed $S$. aureus strains Cowan-1, Newman, SA 113 (83A) and SA U 305 were used. One group of mice was immunised with BSA V fraction as control. Each dose consisted of antigen $20 \mu \mathrm{g}+\mathrm{Al}(\mathrm{OH})_{3}, 20 \mu \mathrm{l}+$ saponin-Quil A $0 \cdot 02 \%, 25 \mu \mathrm{l}$. All mice were immunised with three doses at 1-week intervals and the fourth dose was injected after 7 weeks. Antibody titres were determined by ELISA.

\section{ELISA}

ELISA microtitration plates (Dynatech) were coated overnight at $4^{\circ} \mathrm{C}$ with $100 \mu \mathrm{l}$ of protein solution containing gal-FnBP $2.5 \mu \mathrm{g} / \mathrm{ml}, \beta$-galactosidase $1.5 \mu \mathrm{g} / \mathrm{ml}$ and teichoic acid $1 \mu \mathrm{g} / \mathrm{ml}$. After coating, plates were washed four times with PBS and remaining protein binding sites were blocked with BSA $1 \%$ in PBS at room temperature for $1.5 \mathrm{~h}$. Plates were then washed with PBS-Tween $200.05 \%$ and serum samples were applied in duplicate serial two-fold dilutions in PBS for $1.5 \mathrm{~h}$ at $37^{\circ} \mathrm{C}$. Bound antibodies were detected by incubation $\left(1.5 \mathrm{~h}\right.$ at $\left.37^{\circ} \mathrm{C}\right)$ with horseradish peroxidase-conjugated second antibodies (Dakopatts AB). Bound enzyme was quantified by development of the colour reaction with OPD in sodium citrate buffer, $\mathrm{pH} 5.0$ for $10 \mathrm{~min}$ and measured at $450 \mathrm{~nm}$ in a Titertek Multiscan spectrophotometer.

\section{Purification of $\operatorname{Ig} G$}

Mouse IgG was purified by Protein G-Sepharose affinity chromatography following the manufacturers' recommendations (Pharmacia).

\section{Western blot autoradiography}

Gal-FnBP protein was run on 8-25\% gradient polyacrylamide gels in the Phast system (PharmaciaLKB), dry-blotted at $60^{\circ} \mathrm{C}$ to a nitrocellulose filter which was washed in PBS with Tween $201 \%$, followed by incubation with ${ }^{125} \mathrm{I}-\mathrm{Fn}$ for $2 \mathrm{~h}$ at room temperature. The filter was washed, dried and exposed on XAR-5 X-ray film (Kodak) overnight at $-70^{\circ} \mathrm{C}$. The protein remaining on the gel was stained with Coomassie Brilliant Blue R 250. Alternatively, the nitrocellulose filters were incubated for $2 \mathrm{~h}$ with immune sera diluted 500 times and, after washing with PBS, were incubated with secondary antibodies conjugated with alkaline phosphatase. Filters were then developed with $p$-naphthylphosphate and Fast Blue.

\section{Binding of ${ }^{125}$ I-Fn to bacteria}

Binding of ${ }^{125} \mathrm{I}-\mathrm{Fn}$ to staphylococci and to Streptococcus pyogenes 298 was performed according to Fröman et al. ${ }^{11}$ Briefly, $50 \mu \mathrm{l}$ of ${ }^{125} \mathrm{I}-\mathrm{Fn}$ (c. $2.5 \times$ $10^{4} \mathrm{cpm}$ ), in albumin $0 \cdot 1 \%$ in PBS, was added to $100 \mu \mathrm{l}$ of bacterial suspension $\left(1 \times 10^{9}\right.$ cells $)$. After incubation at room temperature for $1 \mathrm{~h}, 2 \mathrm{ml}$ of ice-cold PBSTween $200.05 \%$ was added and bacteria were centrifuged $(3000 \mathrm{~g}, 15 \mathrm{~min})$. The radioactivity in the pellet was measured in a gamma counter (LKB Wallac). The binding of radioactivity was expressed as the percentage of the total activity added. Blocking of Fn binding to staphylococcal cells by gal-FnBP was performed as above by prior addition of solubilised gal-FnBP.

\section{Blocking of fibronectin binding to staphylococcal cells by antisera}

In blocking experiments, bacteria were preincubated for $1 \mathrm{~h}$ with the sera to be tested at various dilutions and then washed once with PBS. The procedure described above for binding of ${ }^{125} \mathrm{I}-\mathrm{Fn}$ was repeated.

\section{Blocking of Fn binding to immobilised gal-FnBP}

Microtitration wells (Dynatech) were coated with $100 \mu \mathrm{l}$ of gal-FnBP $2.5 \mu \mathrm{g} / \mathrm{ml}$. Unsaturated sites on 
the wells were saturated with BSA, and the wells were incubated with serum samples in two-fold serial dilutions (starting from 1 in 20). After incubation for $90 \mathrm{~min}$ at $37^{\circ} \mathrm{C}$, plates were washed and human $\mathrm{Fn}$ solution was added $(0.1 \mu \mathrm{g} / \mathrm{ml})$ for $90 \mathrm{~min}$ at $37^{\circ} \mathrm{C}$. The amount of bound $\mathrm{Fn}$ was then detected by addition of a horseradish peroxidase-conjugated rabbit anti-human Fn IgG (diluted 1 in 1000) for $90 \mathrm{~min}$ at $37^{\circ} \mathrm{C}$. Blocking activity was calculated as percentage of blocking compared with control experiment in which pooled mouse pre-immune serum was added, also in two-fold serial dilutions.

\section{Results}

\section{Binding of Fn to gal-FnBP}

The smallest part of the gene for FnBP, still coding for efficent Fn binding, was fused to the gene for $\beta$ galactosidase as described in Materials and methods. To demonstrate that this molecule (gal-FnBP) bound to Fn, a Western blot was run and the paper was probed with ${ }^{125} \mathrm{I}-\mathrm{Fn}$ (fig. 1). The table shows $\mathrm{K}_{\mathrm{m}}$ values for binding of human and bovine Fn to $S$. aureus cells and to immobilised gal-FnBP.

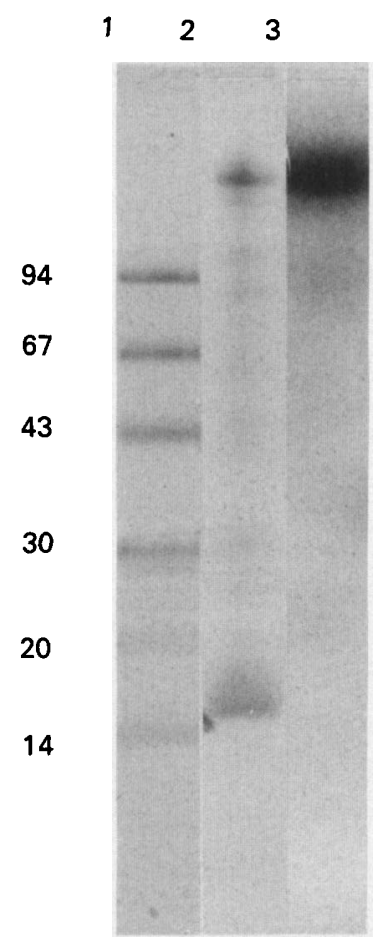

Fig. 1. Autoradiogram of ${ }^{125} \mathrm{I}-\mathrm{Fn}$ bound to gal-FnBP. Lane 1 : mol. wt standards; 2: Coomassie-stained gal-FnBP; 3: autoradiogram.

Table. Affinity of human and bovine Fn to Cowan-1 cells and to immobilised gal-FnBP fusion protein

\begin{tabular}{l|cr}
\hline \multirow{2}{*}{ Fibronectin } & \multicolumn{2}{|c}{$\mathrm{K}_{\mathrm{m}}\left(\mathrm{M}^{-1}\right)$} \\
\cline { 2 - 3 } & Cowan-1 cells & \multicolumn{1}{c}{ gal-FnBP } \\
\hline Human & $6.29 \times 10^{-9}$ & $9.60 \times 10^{-9}$ \\
Bovine & $6 \cdot 10 \times 10^{-9}$ & $17.00 \times 10^{-9}$ \\
\hline
\end{tabular}

\section{Inhibition of Fn binding with gal-FnBP}

FnBP localised on the surface of staphylococci was resistant to heat treatment at $80^{\circ} \mathrm{C}$ for $30 \mathrm{~min}$ as shown by ${ }^{125} \mathrm{I}-\mathrm{Fn}$ binding. On the other hand, incubation of bacteria in formalin $5 \%$ for $48 \mathrm{~h}$ resulted in a considerable decrease of binding ability. Both treatments gave similar results with four $S$. aureus strains, (data not shown). Gal-FnBP fusion protein specifically blocked binding of both human and bovine ${ }^{125} \mathrm{I}-\mathrm{Fn}$ to staphylococcal cells with similar efficiency (fig. 2). Formalin treatment of the gal-FnBP fusion protein gave a $90 \%$ reduction of this blocking ability. Using the protein A-deficient strain SA U305 as carrier gave similar results. No blocking of ${ }^{125}$ I-Fn binding to Str. pyogenes 298 was observed. The effect was independent of the amount of bacteria used in the assay within the range $10^{8}-5 \times 10^{9}$ cells $/ \mathrm{ml}$.

\section{Antigenic properties of FnBP}

Antibodies raised against native $F n$, against galFnBP and against protein A-FnBP were all able to recognise gal-FnBP by Western blotting (fig. 3). The protein A-FnBP fusion protein is a fusion between staphylococcal protein $A$ and the same three 38 aminoacid repeats of FnBP as in gal-FnBP. Antibodies raised against gal-FnBP also recognise native $\mathrm{FnBP}$ in Western blotting (data not shown).

Gal-FnBP fusion protein was then used as an immunogen in mice. Since we had shown above that formalin treatment of gal-FnBP inactivated the Fnbinding ability, immunisation was done with nonmodified antigen or antigen treated with formalin for 2 or 10 days. The antibody titre against FnBP reached a maximum level between 3 and 5 weeks after the first immunisation, irrespective of the antigen modification. No booster effect was observed after the second dose. Antibodies against $\beta$-galactosidase appeared later than those against the FnBP domain (data not shown).

Four heat-killed $S$. aureus strains were used for immunisation, but only strains SA U 305 and SA 113 stimulated antibodies against FnBP (fig. 4). However, high antibody titres against teichoic acid were obtained with all strains, indicating successful immunisations.

\section{Inhibition of Fn binding with sera}

Mouse sera from immunisation with gal-FnBP were tested for the presence of antibodies able to block the binding of Fn to FnBP. Immobilised gal-FnBP was then used as a carrier for ${ }^{125} \mathrm{I}-\mathrm{Fn}$. Fig. 5 shows blocking of ${ }^{125} \mathrm{I}-\mathrm{Fn}$ binding to immobilised gal-FnBP in the presence of sera from mice immunised with formalintreated gal-FnBP or untreated gal-FnBP. Formalin treatment of the antigen used for immunisation resulted in significantly better inhibition than untreated antigen. Approximately equal total antibody titres against FnBP were obtained in the two immunisations. Sera from mice immunised with untreated or 


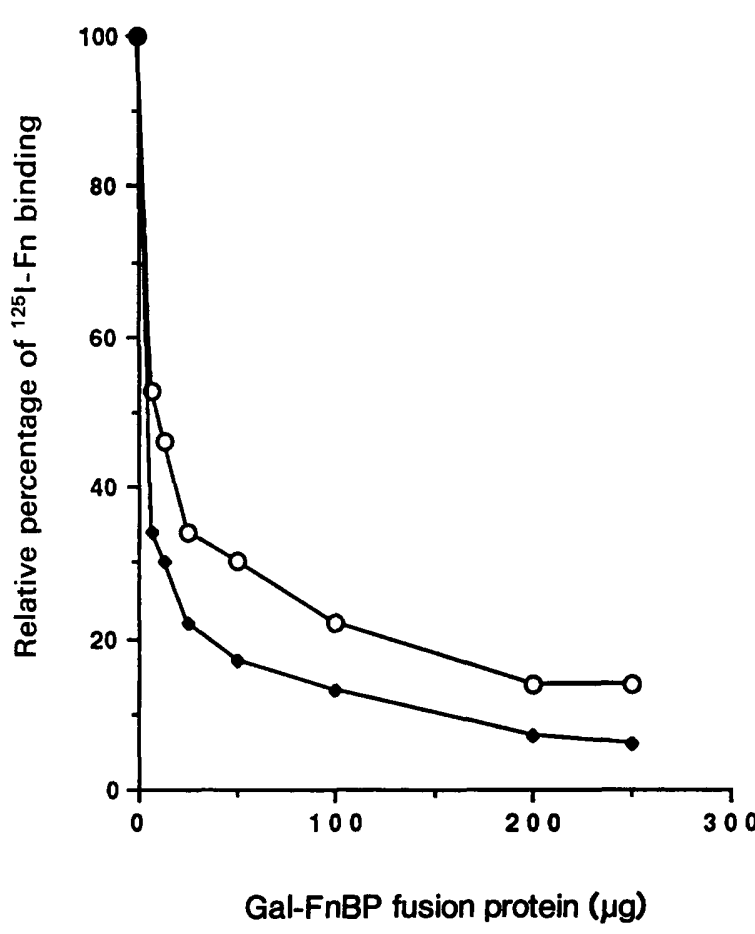

Fig. 2. Inhibition of binding of bovine $(\mathrm{O}-\mathrm{O})$ or human $(-\bullet)$ ${ }^{125} \mathrm{I}-\mathrm{Fn}$ to $S$. aureus SA113 (83A) by gal-FnBP fusion protein.

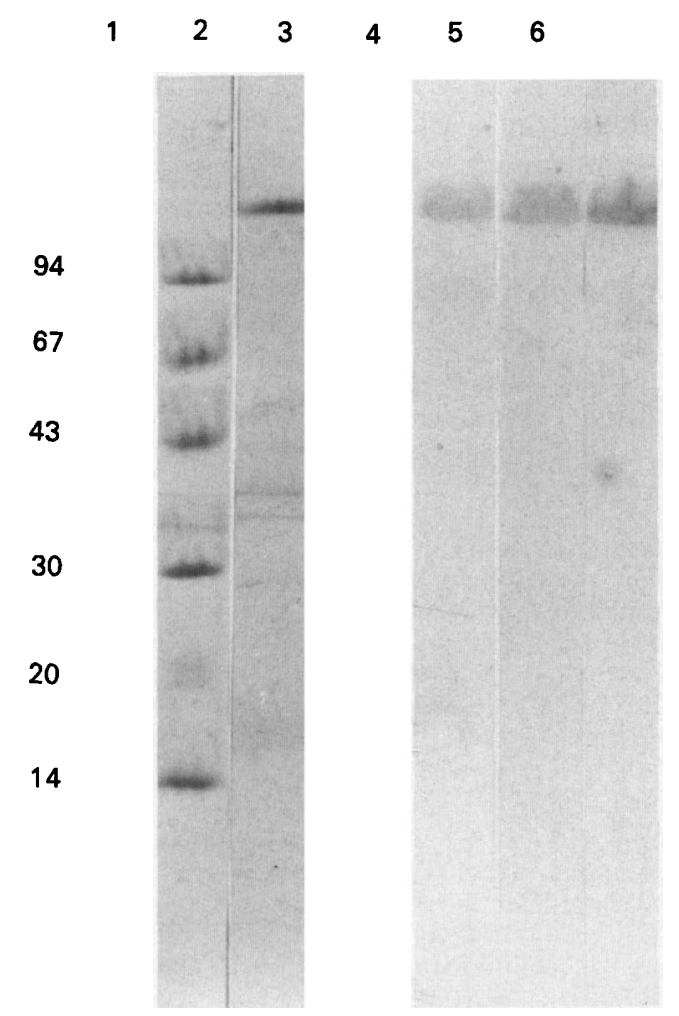

Fig. 3. Western blotting. The antigen run in each lane was gal-FnBP probed with various rabbit sera. Lane $1, \mathrm{~mol}$. wt standards; 2 , Coomassie-stained gal-FnBP; 3, probed with pre-immune serum from rabbit subsequently immunised with gal-FnBP; 4 , probed with gal-FnBP antiserum; 5 , probed with antiserum against native FnBP; 6, probed with protein A-FnBP antiserum.

formalin-treated whole $S$. aureus cells were unable to block binding of Fn to gal-FnBP (data not shown). Similarly, pre-immune sera failed to inhibit binding.

Another blocking assay was done employing whole staphylococcal cells as the carrier for FnBP and ${ }^{125}$ I-

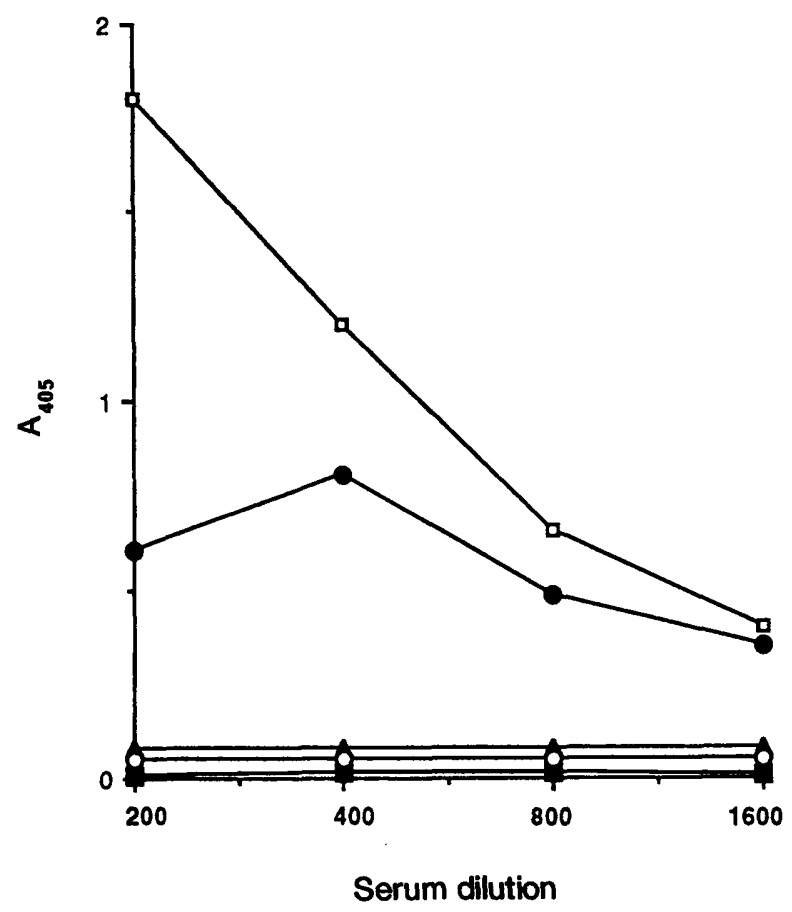

Fig. 4. Antibody titre against gal-FnBP fusion protein generated by immunisation of mice with heat-killed staphylococci: $S$. aureus SA U305 heat-killed ( $\square-\square)$; S. aureus SA 113 heat-killed (०-O); $S$. aureus Newman heat-killed ( $\mathbf{\square}-\mathbf{\square})$; S. aureus Cowan heat-killed $(\boldsymbol{\Delta}-\boldsymbol{\Delta})$; pre-immune $(\mathrm{O}-\mathrm{O})$.

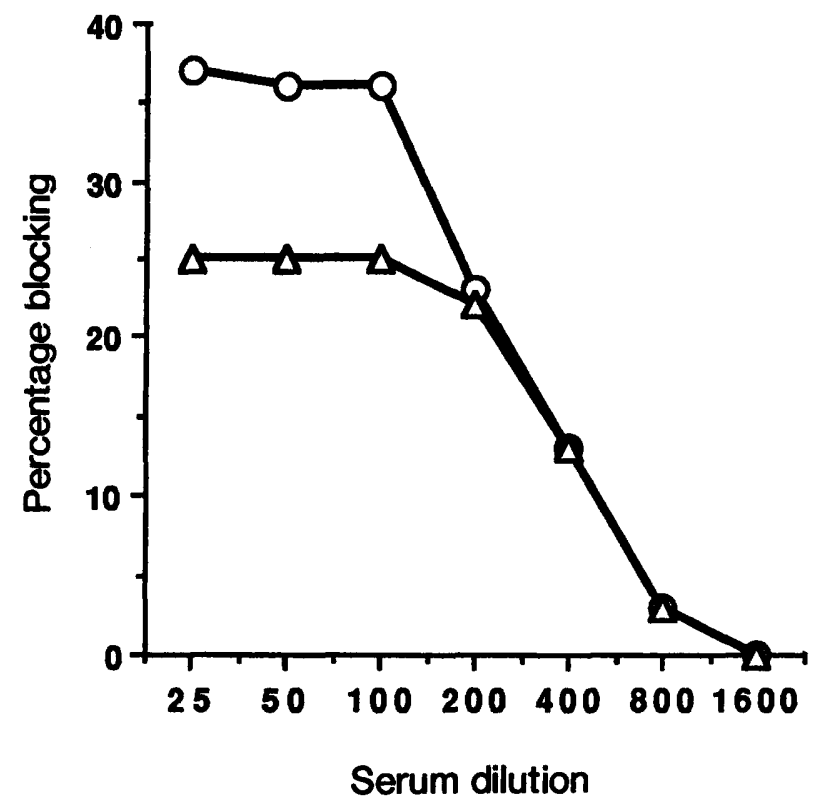

Fig. 5. Blocking titres in sera from mice immunised with gal-FnBP fusion protein: blocking antibodies from formalin-treated $(\mathrm{O}-\mathrm{O})$ and from unmodified gal-FnBP $(\triangle-\triangle)$.

Fn. In this assay no specific blocking activity by the sera could be detected. However, a non-specific blocking activity was found in pre-immune sera. Sera depleted of Fn or IgG purified from the sera displayed no non-specific inhibition of Fn binding (data not shown).

\section{Discussion}

We have investigated whether antibodies against the staphylococcal FnBP block attachment of bacteria to 
extracellular matrix proteins of host tissues. If this is the case, FnBP might serve as a component of an antistaphylococcal vaccine. We have chosen to use a blocking assay that directly measures the interaction of sera on the binding of Fn to FnBP, employing purified molecules. This allowed us to see the effect of such antibodies alone, independent of other bacterial attachment mechanisms. However, a future antistaphylococcal vaccine may have to be a mixture of collagen-binding protein, FnBP, vitronectin-binding protein etc.

The FnBP from $S$. aureus was found to be unstable and obtainable only in limited amounts. ${ }^{11}$ Purification of FnBP on Fn Sepharose was more difficult than expected. To overcome this problem, a gene fusion was constructed encoding a fusion protein encompassing $\beta$-galactosidase from $E$. coli and the portion of the FnBP responsible for binding. This protein (galFnBP) was shown to retain its binding specificity and cross-react immunologically with native FnBP. Thus, it was considered suitable for the immunisation studies, especially since it can be obtained in large quantities as inclusion bodies. Binding of human or bovine Fn to $S$. aureus was inhibited up to 95 and $88 \%$ respectively, by prior addition of gal-FnBP fusion protein. This confirms the specificity of the experimental system used.

Specific interactions of Fn, present in body fluids and associated with macrophages, ${ }^{16}$ with gal-FnBP can create problems during immunisation. Such neutralisation of the FnBP antigen would be expected when whole staphylococcal cells are used for immunisation. To exclude the interference between Fn and FnBP we modified the FnBP to eliminate its binding, but preserve its antigenicity. The rationale for using formalin-inactivated gal-FnBP is to avoid its immediate binding to endogenous host Fn, that may sterically hide important antigenic epitopes. FnBP localised on the surface of staphylococci retains its binding capacity after heating to $80^{\circ} \mathrm{C}$ for $30 \mathrm{~min}$; thus it is an unsuitable way to modify the bacterial antigen or gal-FnBP. Formalin-treatment of $S$. aureus caused a significant drop in Fn binding capacity.
Similar treatment of gal-FnBP reduced its binding by $90 \%$ whereas its immunogenicity was retained.

In the blocking assay we found a significant difference between the groups of mice immunised with formalin-treated (about $40 \%$ blocking) or non-treated gal-FnBP (about $25 \%$ blocking). Lack of blocking by sera from mice immunised with staphylococcal cells indicates that the location of FnBP within the bacterial surface is hidden somehow and not recognised by the host immune system. Immunisation with four different heat-killed $S$. aureus strains gave markedly different titres against gal-FnBP, implying a different exposure of FnBP on different strains (fig. 4).

We have previously shown that rabbit sera containing antibodies against gal-FnBP have blocking capacity. ${ }^{17}$ We have also found (unpublished studies) that c. $40 \%$ of sera from human patients with $S$. aureus infections had increased titres against gal-FnBP but none of these sera were able to block binding of Fn to immobilised gal-FnBP. These findings indicate that "blocking antibodies" do not occur during infection (or immunisation with staphylococci), but once generated may participate in protection against staphylococcal colonisation of the extracellular matrix of various tissues.

In conclusion, we have found that mice immunised with gal-FnBP or with whole $S$. aureus cells produce antibodies against FnBP. However, only with the galFnBP fusion protein as an immunogen were blocking antibodies obtained. Such blocking ability of the antibodies could be detected only by a blocking assay based on immobilised gal-FnBP, but not one based on whole staphylococcal cells. Therefore, we believe that the gal-FnBP, and similar types of molecules, especially after formalin treatment, may have a potential as components of a future vaccine against $S$. aureus infections.

We would like to thank Dr H. Krotkiewski (Department of Carbohydrate Chemistry, University of Lund) for help during the purification of IgG. This study was supported by grants from the Swedish Medical Research Council (16X-04723) and by a grant from Industrifonden to Alfa Laval, Tumba, Sweden and the Medical Faculty of Lund University.

\section{References}

1. Beachey EH. Bacterial adherence: adhesion-receptor interactions mediating the attachment of bacteria to mucosal surfaces. $J$ Infect Dis $1981 ; 143$ : 325-345.

2. Chhatwal GS, Preissner KT, Müller-Berghaus G, Blobel H Specific binding of the human $\mathrm{S}$ protein (vitronectin) to streptococci, Staphylococcus aureus and Escherichia coli. Infect Immun 1987; 55: 1878-1883.

3. Holderbaum D, Hall SG, Ehrhart LA. Collagen binding to Staphylococcus aureus. Infect Immun 1986; 54: 359-364.

4. Kuusela P. Fibronectin binds to Staphylococcus aureus. Nature 1978; 276: 718-720.

5. Lopes JD, dos Reis M, Brentani RR. Presence of laminin receptors in Staphylococcus aureus. Science 1985; 229. 275-277.

6. Usui Y. Biochemical properties of fibrinogen binding protein (clumping factor) of the staphylococcal cell surface. Zentralbl Bakteriol Mikrobiol Hyg A 1986; 262: 287-297.

7. Wadström T, Switalski L, Speziale P et al. Binding of microbial

pathogens to connective tissue fibronectin: an early step in localized and invasive infection. Heidelberg, Springer Verlag. 1985: 193-207.

8. Mosher DF. Fibronectin. Prog Hematol Thromb 1980; 5: $111-151$

9. Vercellotti GM, Lussenho D, Peterson PK et al. Bacterial adherence to fibronectin and endothelial cells: a possible mechanism for bacterial tissue tropism. $J$ Lab Clin $\mathrm{Med}$ 1984; 103: 34-43.

10. Kuusela P, Vartio T, Vuento M, Myhre EB. Binding sites for streptococci and staphylococci in fibronectin. Infect Immun $1984 ; 45: 433-436$

11. Fröman G, Switalski L, Guss B, Lindberg M, Höök M, Wadström T. Characterization of the fibronectin binding protein of Staphylococcus aureus. In: Normark S, Lark D (eds) Protein carbohydrate interactions in biological systems. London, Academic Press. 1986: 262-268.

12. Flock J-I, Fröman $\mathrm{G}$, Jonsson $\mathbf{K}$ et al. Cloning and expression of the gene for a fibronectin-binding protein from Staphylococcus aureus. EMBO J 1987; 6: 2351-2357. 
13. Signäs C, Raucci G, Jönsson K et al. Nucleotide sequence of the gene for a fibronectin-binding protein from Staphylococcus aureus: use of this peptide sequence in the synthesis of biologically active peptides. Proc Natl Acad Sci USA: 1989; 86: 699-703.

14. Vuento M, Vaheri A. Purification of fibronectin from human plasma by affinity chromatography under non-denaturing conditions. Biochem $J$ 1979; 183: 331-337.

15. Stanley K, Luzio JP. Construction of a new family of high efficacy bacterial expression vectors: identification of cDNA clones coding for human liver proteins. $E M B O J$ 1984; 3: 1429-1434.

16. Alitalo K, Hovi T, Vaheri A. Fibronectin is produced by human macrophages. J Exp Med 1980; 151 : 602-613.

17. Luk JM, Flock JI, Wadström T. Detection in rabbit sera of blocking antibodies against staphylococcal fibronectinbinding protein by enzyme-linked immunosorbent assay. FEMS Microbiol Immunol 1989; 1: 505-510. 